\title{
Paroxysmal Supraventricular Tachycardia in Children : The Role of Infectious Diseases and Its Relationship to Serum Enzyme.
}

\author{
by \\ A. SAMIK WAHAB \\ (From the Department of Child Health, School of Medicine \\ Gadjah Mada University, Yogyakarta)
}

\begin{abstract}
The records of 28 children whose first episode of paroxysmal supraventricular tachycardia occurred before 12 years (median age 10 months) were reviewed. There were 17 males and 11 fermales. In 17 cases the first attack occurred before the first year and in 11 of these it occurred after the first year. One case had congenital heart disease (ASD). The WPW syndrome was diagnosed in 3 cases. When first seen, most of the infants presented with signs of incipient or manifest congestive heart failure. In almost ninetenth of cases there was an increased of serum enzymes (lactic dehydrogenase, creatinephosphokinase and glutamic oxaloaccetic transaminase. Digitals was effective against congestive heart failure and when continued, might prevent failure during subsequent attacks. Antiarrhythmic agents other than digitals were not used. It is recommended to continue digitalis treatment for at least one year in all patients with SVT, whether or not the first episode terminated spontaneously.
\end{abstract}




\section{Introduction}

Paroxysmai supraventricular tachycardia (PSVT) is a fast, ectopic rhythm originating within the atria or the junctional tissue; characteristically, the paroxysm begins and ends suddenly. The tachyarrhythmia is often named by the site or origin of the ectopic rhythm - e.g. atrial tachycardia, nodal tachycardia or junctional tachycardia (Agarwala and Levy, 1980). The heart rate ranges from 180 to 300 beats per minute with completely regular QRS complexes. $P$ waves may be difficult to distinguish because they are often superimposed on the preceding T waves (Krovetz et. al., 1979). Although the mechanism of PSVT is unknown, various explanations have been proposed: atrio-ventricular (AV) node reentry, sinoatrial (SA) node reentry, concealed anomalous pathways, reentry through AV nodal bypass, atrial ectopic focus or junctional ectopic focus (Agarwala and Levy, 1980).

The quoted incidence of $1 / 25.000$ is based upon an estimate made in 1967 (Keith et al., 1967). However, in the intervening 22 years, methods of detection have improved and awareness of the condition has increased. In addition, during the las decade the number of children who have had cardiac surgical procedures has increased, and PSVT has become recognized as one of the late sequelae of these prosedures. For these reasons, we believe that PSVT is much more common than originally estimated (Garson et al., 1981).

In 1976 we reported 10 cases of PSVT out of 28 children suffering from acute gastroenteritis with dehydration (Wahab et al., 1976). We also reported 25 cases of PSVT aged 10 days to 10 years, during the period between 1982 - 1984, amongst 2668 patients admitted to Child Health Department, Faculty of Medicine/Dr. Sardjito Hospital, Gadjah Mada University (Wahab and
Setiyono, 1984); and during the period of January 1984 to December 1984 we also reviewed 37 cases aged 7 days to 8 years from the same institution (Wahab, 1986a).

The etiology of the PSVT cannot always be identified. Agarwala and Levy (1980) studied 41 patients with PSVT where in 50 percent of cases no cause could be detected. Most of the patients with PSVT of unknown etiology were under four months of age and were males. In the neonatal period, Wolf-Parkinson-White (WPW) syndrome was associated with PSVT in 58 percent of cases. The reported incidence of PSVT associated with congenital heart disease (with or without WPW syndrome) varies from 8 to 26 percent. Viral infections had also been related to a high incidence of PSVT. Wahab (1986 a) reviewed 37 cases of PSVT and found most of them to be patients with probable viral infection $(73 \%)$ i.e. gastroenteritis, encephalitis and meningoencephalitis. Park et al. (1983) also found that pertussis vaccine administration could precipitate PSVT.

Some viral infections can affect the heart causing myocarditis (Giustra and Nilsson, 1950). Measles myocarditis cases especialy those who died had lactic dehydrogenase ( $\mathrm{LDH}$ ) levels similar to those recorded in adults with myocardial infarction (Wooldridge, 1985). LDH and glutamine oxalo transaminase (GOT) are also employed as indicators of tissue breakdown and, if positif, are helpful confirmatory evidence of active myocardial disease (Chesler, 1958). Creatinine phosphokinase is also found in the heart, liver and skeletal muscle (Mille and Weller, 1975). Wooldridge (1985) found a correlation between elevation of these enzyme serum levels and ECG abnormalities in measles patients with broncho-pneumonia.

The purpose of this study is to review the records of 28 cases of PSVT, their subsequent courses and identify factors which might be predictive of the prognosis, especially in relation to the rising of serum GOT,

\section{Materials and Methods}

All patients with the above definition are included in the study. They had to have at least one surface electrocardiogram with a sustained episode (greater than one minute) which met one of the following four criteria; 1) $\mathrm{P}$ waves visible with an abnormal $\mathrm{P}$ wave axis $\left(91^{\circ}\right.$ to $\left.359^{\circ}\right)$ and a $\mathrm{P}$ wave rate more rapid than normal for age; 2) $\mathrm{P}$ waves visible with a normal $\mathrm{P}$ wave axis $\left(0^{\circ}\right.$ to $90^{\circ}$ ) and a $\mathrm{P}$ wave rate over $240 /$ minute or a $\mathrm{P}$ wave rate more rapid than normal for age with documented sudden onset or sudden termination; 3) $\mathrm{P}$ waves not visible with a QRS rate more rapid than normal for age and a normal duration of the QRS complex; 4) $\mathrm{P}$ waves visible with a normal $P$ wave axis, and atrioventricular dissociation with a QRS are more rapid than normal for age and normal duration of QRS complex. Patients with atrial fibrillation or atrial flutter (defined solely by surface ECG) were excluded as was the case in the study of Garson et al., (1981). Other criteria for entry into the study was that the patien should be less than 15 years of age wher the first episode of SVT occurred. Twenty eight patients of such were identified in the period between 1986 to 1988 among 5275 patients nursed, consisting of 17 males and 11 females.

The record of each patient was reviewed for the following items: age of onset of SVT, sex, predisposing factors, presence of fever, presence of congestive heart failur in the first episode, presence of anemia (by
$\mathrm{LDH}$ and CPK that are found in heart, liver and skeletal muscle. We also discussed the influence of nutritional and anemic status of these patients in relation to supraventricular tachycardia.

measuring hemoglobin content and hematocrit) and undernutrition. We also reviewed the description of ECG in SVT (ventricular rate, atrial rate, presence and axis of $\mathrm{P}$ waves, description of $\mathrm{QRS}$ complex), description of ECG in sinus rhythm for pre-excitation and bundle branch block type for acute treatment fo the first episode and responses to treatment (success was defined as a cessation of SVT for at least 8 hours), type of intial long-term treatment (on discharge from first hospitalisation or clinic visit), and responses to such treatments were also reviewed.

Hemoglobin content was measured by cyanmethaemoglobin spectrophotometric method (Dasie and Lewis, 1975). The criteria for anemia was the WHO (1972) standard, where $\mathrm{Hb}$ level $12 \mathrm{~g} \%, 11 \mathrm{~g} \%$ and $10 \mathrm{~g} \%$ was considered normal for 5 to 12 years, 2 to 5 years and $0-2$ years old children respectively. The WHO standard for nutritional state (WHO), 1983) was also used where the weight values of 2 standard deviations or more below the median weight for age of the reference population were considered as undernutrition. GOT, LDH and CPK enzyme levels were measured by spectrophotometric method (Henry, 1984).

Statistical analysis of continuous data was performed using the student $t$ test; analysis of categorial data was performed using chi-square. Statistical significance was inferred in the probability of the difference occurring by chance was 0,05 or less. 


\section{Results}

Relative incidence and age and sex distribution.

During the period of 1986 to 1988 there were 28 PSVT cases admitted to Department of Child Health Faculty of Medicine Dr. Sardjito Hospital amongst 5275 pe-

Table 1 : Age at onset of PSVT and sex

\begin{tabular}{lccc}
\hline \multirow{2}{*}{ Age (Years) } & \multicolumn{2}{c}{ Sex } & Total \\
\cline { 2 - 3 } & Male & Female & 17 \\
\hline $0-$ & 11 & 6 & 5 \\
$1-$ & 3 & 2 & 2 \\
$3-$ & 1 & 1 & 0 \\
$5-$ & 0 & 0 & 1 \\
$7-$ & 1 & 0 & 3 \\
$9-12$ years & 1 & 2 & 28 \\
\hline Total & 17 & 11 &
\end{tabular}

Our group consisted of 17 males and 11 females $(1.5: 1)$. We found no statistical difference between males and females cases (chi-square, $\mathrm{p}>0,05$ ).

Predisposing and precipitating factors.

In this series, we found only one case with congenital heart disease (ASD) in combination with Wolf-Parkinson-White Syndrome (WPW Syndrome). The other three cases had WPW syndrome during sinus rhythm.

Ten out of 28 patients $(36 \%)$ were undernourished. The prevalence of underin school children in Yogyakarta in 1985 was

diatric admission. The age range when PSVT began was from 1.5 month to 12 years (median 10 months). PSVT appeared at one year of age of less in $61 \%$, over 1 year in $39 \%$ (Table 1).

$17 \%$ (Wahab, 1986b). Anemia was found in 5 out of 28 cases $(21 \%)$ and this rate is higher than the prevalence of anemia in Yogyakarta i.e. 11.7\% (Wahab, 1986b).

\section{Enzymes}

Almost in all PSVT cases except four serum was obtained for enzyme analysis Normal values of these enzymes were as follows : LDH : $80-240 \mathrm{U} / \mathrm{dl}$. CPK : $0-50$ $\mathrm{U} / \mathrm{dl}$ and GOT : $1-9 \mathrm{U} / \mathrm{dl}$. It revealed that 21 out of $24(87.5 \%)$ had more than normal enzyme values. The mean enzyme values in the 21 patients are depicted in table 2 .

Table 2 : Enzyme values in the 21 patients

\begin{tabular}{|c|c|c|c|}
\hline Enzymes & Range (U/dl) & Mean & Standard crror \\
\hline LDH & $25-5786$ & 625.00 & \pm 274.76 \\
\hline CPK & $20-2035$ & 207.52 & \pm 107.20 \\
\hline GOT & $13.6-248$ & 57.52 & $\pm \quad 14.55$ \\
\hline
\end{tabular}

Symptoms and signs during tachycardia The common symptom noted before admission was a change of color. Thus cyanosis and pallor was seen in 13 patients $(46 \%)$. Other symptoms reported were rapid peripheral or precordial pulsa-

tion, rapid respiration, irritability, vomiting, refusal to eat and weakness. These symptoms occurred in about half of the patients and most of them had two, three or more symptoms together.

Table 3 : Predisposing factors

\begin{tabular}{|r|l|c|c|}
\hline No. & Diagnosis on admission & Number of cases & Mortality \\
\hline 1. & Gastroenteritis & 1 & - \\
2. & Gastroenteritis with moderate or severe dehydration & 3 & 1 \\
3. & Gastroenteritis with sepsis & 1 & - \\
4. & Bronchopneumonia & 3 & 1 \\
5. & Encephalitis & 1 & - \\
6. & Meningoencephalitis & 2 & - \\
7. & Encephalitis and bronchopneumonia & & - \\
8. & Typhoid fever \& encephalitis & 3 & 2 \\
9. & Chronic rhinitis & 2 & 1 \\
10. & Dengue haemorrhagic ferer will shock & 2 & 1 \\
11. & Septic shock & 2 & - \\
12. & Septicemia & 1 & - \\
13. & Asthma bronchiale & & \\
14. & Hydrocephalus & & \\
\hline
\end{tabular}

The majority of children ( $89 \%$ ) were admitted for infectious disease (Table 3 ), that is why most of them $(89 \%)$ had fever before their attack. Other causes were heart failure, chest pain and ASD.

\section{Electrocardiographic features}

ECG during SVT. The ECG during the first episode of SVT could be performed in 28 patients. The mean heart rate during SVT was $197 \pm 3.4(\mathrm{SEM}) /$ minute (Table

Table 4: Heart rate and age

\begin{tabular}{|l|c|c|}
\hline Age (Years) & No. & Heart rate mean \pm SE \\
\hline$<1$ & 17 & $193.47 \pm 3.73$ \\
$1-15$ & 11 & $202.55 \pm 6.19$ \\
\hline
\end{tabular}

$I_{11}=1.7145$

$1_{5 \%}=2.074$

0,05
4). $P$ waves were visible on the surface $E C G$ in 19 out of 28 cases $(68 \%)$ during SVT. The presence of a $P$ wave was inferred if the $T$ wave was quite pointed or if a notch was visible on the $T$ wave. The $P$ wave axis could be estimated on all visible $P$ waves. The most common $P$ wave axis was $45^{\circ}$ to $60^{\circ}$ i.e. positive in lead I, II, aVF, III and aVL or flat in lead aVL. There was no AV block. All of the QRS complex during SVT has a normal duration and configuration. 
ECG in sinus rhythm. Wolf-ParkinsonWhite syndrome was found during sinus rhythm on surface ECG in 3/28 (11\%) patients. Right bundle branch block (RBBB) was found in one patient $(3 \%)$.

\section{Treatment of attacks}

Although most of the children were very seriously ill with congestive heart failure on admission, considerable improvement followed the initiation of digitalis treatment given shortly after ECG-verification of tachycardia irrespective of the presence or absence of WPW. In all cases digitalis was given alone, without other antiarrhythmic drugs (e.g. calcium antagonist or betablockers).

Intravenous cedilanid $(0,02$ to $0,03 \mathrm{mg}$ $\mathrm{kg}$ total digitalizing dose) for unconscious patients or oral digoxin $(0,04$ to $0,06 \mathrm{mg} / \mathrm{kg}$ total digitalizing dose) for conscious ones was most frequently used and was succesful in $19 / 28$ patients $(68 \%)$. The median time from digitalis administration to cessation

\section{Discussion}

The present data do not allow any evaluation of the incidence of paroxysmal tachycardia among infants and children in the population. The number of cases was relatively small if compared with that of Garson et al (1981) and Anderson et al (1973) who studied 217 and 62 children with PSVT, respectively. As mentioned earlier the frequency of PSVT in the years 1986, 1987 and 1988 in our hospital was 28 out of 5275 patients nursed or $5.3 \%$. In 1986 the frequency had been reported by Wahab to be $9 \%$ and $24 \%$, respectively (Wahab, 1966 and 1986).

The male predominance reported by other authors (Nadas, 1952; Lundberg. 1952) could not be substantiated statistically by our data though male were more than of SVT was eignt hours. Success was unrelated to age, presence of $\mathrm{CHF}$, heart rate or other ECG features. Maintenance treatment was given until three months.

\section{Prevention of attacks}

Digitalis was used to prevent attacks in a total of 19 patients. All these patients had no episode of repeated tachycardia in the first three months.

\section{Prognosis and Mortality}

Nine out of 28 patients died in the first day of attack (Table 3). One case died of severe dehydration with irreversible shock, one case with bronchopneumonia, two cases with encephalitis, two cases with dengue hemorrhagic fever with shock and two cases with septic shock and septicemia. All three cases with WPW syndrome in sinus rhythm survived. The overal mortality of SVT then was about $30 \%$ during three years.

female cases (Table 1). The incidence of congenital heart disease was $3.6 \%$, compared with our earlier published figures of $2.7 \%$ (Wahab, 1984) and 4\% (Wahab, 1986) These figures were very small if compared with figures from Anderson (1973), Nadas (1952) and Simcha and Bonham-Carter (1971) i.e. 11,20 and $34 \%$ respectively. The precentage of patients with WPW syndrome in our series was as high as $11 \%$ while other authors have reported incidences ranging from $12-56 \%$ (Anderson, 1973; Lundberg, 1963; Simcha and Bonham-Carter, 1971)

The heart rate during tachycardia was not significantly different statistically in children under and above one year (Table 4). Other studies using the age of 4 months as cutt of point found the heart rate significantly higher in infants under 4 months.

Furthermore it appears from our series that infectious diseases are predominant (89\%). Our earlier published reports revealed that $73 \%$ and $100 \%$ had had infectious diseases (Wahab, 1984, 1986a), while other authors has reported only $3,69 \%$ of patients with infectious diseases (Garson et al., 1981).

Undernourishment and anemic state of children may predispose to PSVT. In our series $36 \%$ of our PS JT children suffered from undernutrition, and $21 \%$ had anemia. Our earlier report found $46 \%$ undernourished and $58 \%$ anemic children. These results, however, are not consistent.

It is well known that the highest concentration of LDH, CPK and GOT are found in the liver, heart and skeletal muscle. So if there is a rising of enzyme levels, myocardial damage might have occurred. Twenty one out of 24 PSVT patients had increased enzyme levels. It means that the possibility of myocarditis in our series is $87.5 \%$. This figure is much higher than our earlier figure of $45.5 \%$ (Wahab, 1986a) and much higher than the figure of Garson et al. (1981) i.e. $1.38 \%$.

Digitalis was the drug most commonly used to treat attacks of tachycardia in our series. Sinus rhythm was restored within hours our a day; with a median of 8 hours. Digitalis was continued until three months to prevent recurrence, but Garson et al. (1981) suggested to continue this drug until a year especialy if PSVT begins after the age of 6 months. The main importance of digitalis was undoubtedly its efficacy in the treatment of congestive heart failure during attacks of tachycardia in infants and its possible role in the prevention of congestive failure during recurrent attacks. In our opi- nion, this remains the main indication for digitalis in PSVT in infancy and children. Anderson et al. (1973) thought that digitalis might not be necessary in older children and even in children over the age of one year it was rarely needed. Presence of WPW might, according to some authors (Schamroth, 1979) had been considered a contraindication for the use of digitalis. However in our series, no serious side effects of digitalis at all were observed.

Other drugs can be used to treat PSVT attacks i.e. verapamil that belongs to the calcium antagonist group. It can be given intravenously at the beginning of an attack and its effect is very good.

In our series there were $9 / 28$ deaths $(30 \%)$; it did not correspond to the PSVT itself, but the underlying disease was probably more dominant as the cause of death. Keith et al. (1967), Lundberg (1963) and Nadas et al. (1972) found mortalities ranging from 2 to $11 \%$, most often due to other serious diseases including cardiac malformations.

In conclusion it may be stated that PSVT is not a rare condition in infancy and childhood especially when suffering from infectious diseases particularly severe dehydraion due to gastroenteritis, dengue hemorrhagic fever with shock or encephalitis. These patients often have myocarditis leading to heart failure. The heart failure itself, however, can readily be controlled by the use of digitalis. The results of prevention and treatment are encouraging: fortunately, after infancy the discomfort caused by the disease is usually limited. Restriction of the patient's physical activity is rarely needed and should be held at a minimum though exertion and excitement may in some cases provoke attack. 


\section{Recommendation}

Since we have found that the recurrence rate can be significantly decreased with treatment, we recommend that all infants and children with PSVT receive longterm drug therapy. Based upon the data of $\mathrm{Na}$ das et al. (1972) and Anderson et al. (1973), we suggest that if PSVT begins before 6 months, therapy be continued for one year. If PSVT begins after the age of 6 months

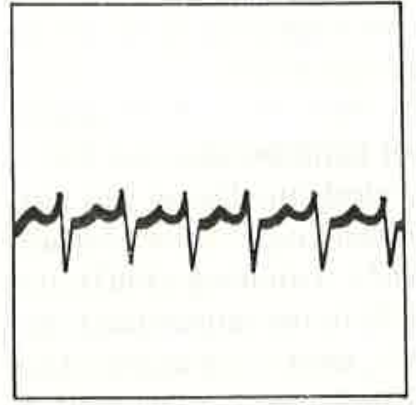

$\mathbf{A}_{1}$

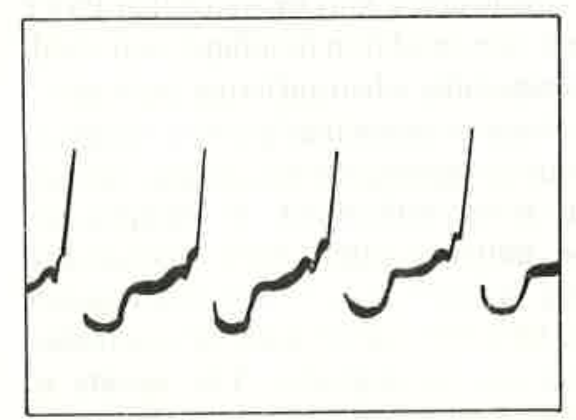

$\mathrm{B}_{1}$

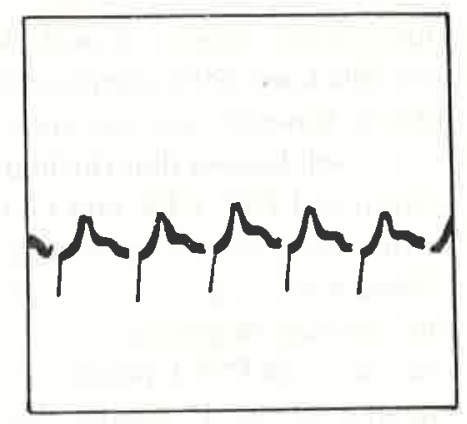

$\mathbf{A}_{2}$

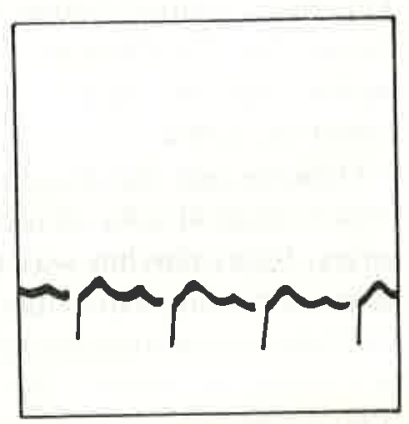

$\mathrm{B}_{2}$ therapy should be for at least one year, but the patients and parents should be warned that recurrence may continue more than a year after the onset of PSVT. In planning the possible underlying disease such as anemia, undernutrition and all infections that rise body temperature.

\section{REFERENCES}

1. Agarwala, B.N.; Levy, H.B.: Paroxysmal supraventricular tachycardia in the infant. Physic. 22: 3: $144-9$ (1980).

2. ANDERSON, E.D.; JACOBSEN, J.R.; Sandoe, E.; Videbaek, J.; WENNEVOLD, A.: Paroxysmal tachycardia in infancy and childhood I Paroxysmal Supraventricular Tachycardia. Acta Paediat. scand. 62: 341-8 (1973).

3. CHESLER, E.: Serum glutamine oxalocetic transaminase levels in diphtheritic myocarditis. Br. Heart. J. 20, 24-7 (1958).

4. DAVIE, JV.; Lewis, S.M. : Practical haematology $5^{\text {th }}$ ed. pp. (Churchil Livingstone, London, 1975).

5. GARSON, A.; Gillette, P.C. and Mc Namara, D.G.: Supraventricular tachycardia in children: Clinical features, response to treatment, and longterm follow-up in 217 patients. J. Pediat. 98: 87582 (1981)

6. GIUSTRA, F.X.; Nilsson, D.C.: Myocarditis following measles. J. Dis.Child. 79: 487-90 (1950)

7. HENRY, J.B.: Clinical Diagnosis and Míanagement by Laboratory method; $7^{\text {th }}$ ed. (W.B. Saunders, Tokyo 1984)

8. KEITH, J.D.; Rowe, R.D.; Viad, P.: Heart disease in infancy and children; $2^{\text {nd }}$ ed. p 1057 (Mac Millan, New York 1967).

9. KROVETZ, L.J.; GESSNER, I.H.; SCHEIBER, G.L.: Pediatric Cardiology (Pitman Medical, London 1979).

10. LUNDBERG, O.: Paroxysmal tachycardia in in fancy. A clinical and experimental study. Acta paediat. scand. suppl. 143-7 (1963)

11. MILLER, S.E.; WELLER, J.M.: Textbook of clinical pathology; $2^{\text {nd }}$ ed. pp.(William \& Wilkins, Baltimore 1975)
12. NADAS, A.S.; Daeschner, C.W.; Roth, A. Blumenthal, St. Paroxysmal tachycardia in infants and children. Paediatrics 9: $167-70$ (1952)

13. PARK, J.M: LEDBETTER, EO; SOUTH, M.A.; SINDARMONT, S. MIRKOVIC, R.R Paroxysmal supraventricular tachycardia precipitated by pertussis vaccine. J. Pediatr 102 883-6 (1983).

14. SCHAMROTH, L.: The disorders of cardiac rythm; pp. 293 (Blackwell Scient Publ, Oxford, Edinburg 1971)

15. SINCHA, A.; BONHAM-CARTER, R.E Paroxysmal atrial tachycardia in infants and children. Lancet i : 832-6 (1971).

16. WAHAB, A.S.; ACHMAD SURJONO; MARWOTO: ECG changes on severe dehydration in children. 5 ${ }^{\text {th }}$ Asian Pacific Congress of Gastroenterology Singapore 23-27 May 1976.

17. WAHAB, A.S., SETIYONO: Takhikardi supraventrikuler pada anak yang dirawat nginap di RSUP Dr. Sardjito Kumpulan Naskah Pertemuan Ilmiah HUT II RSUP Dr. Sardjito, Yogyakarta 9-11 Februari 1984

18. WAHAB, A.S.: Paroxysmal supraventricular tachycardia in children : Clinical features and response to treatment. Paediatr. Indones. 26: 127 -36 (1986a).

19. WAHAB, A.S.: Takhikardi Supraventrikular paroksismal pada Anak. Peranan penyakit infeksi dan kemungkinan kenaikan kadar enzim dalam serum. Berkala I. Ked. 18 (3): 137-47 (1986b).

20. WOOLDRIDGE, M.A.W.: Sudden death in measles and its relationship to serum enzyme and electrocardiographic changes. J. trop. Ped. 31 (3): $160-62(1985)$.

Fig $1: A_{1}$ SVT at a rate of 220/minute. $P$ waves are not visible. $A_{2}: S V T$ at a rate of $195 /$ minute. $P$ waves are visible. $B_{1}:$ ECG patterns with WPW syndrome. $B_{2}$ : ECG pattern with sinus rythm. Note : All surface ECG tracings were take at the usual paper speed (25 $\mathrm{mm} /$ second) with usual standardization $(1 \mathrm{mV} / 10 \mathrm{~mm}$ ). 